\title{
Editorial
}

\section{Spinal trauma}

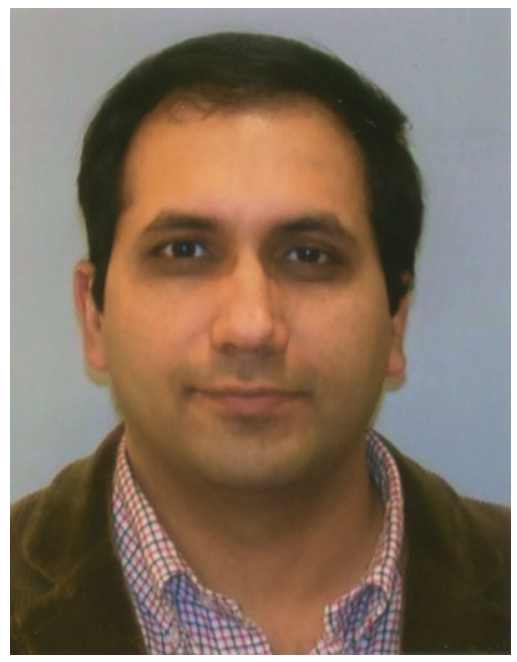

The history of the way spinal trauma has been managed over the last $80-90$ years is extremely interesting. Ever since Roentgenograms were invented, there have been numerous attempts to clarify the patterns of spinal trauma and to classify these injuries. Boehler ${ }^{1}$ was amongst the first in 1930 to give terms to some of the injury patterns. Holdsworth ${ }^{2}$ in 1963 gave the two column concept, stating that the integrity of the posterior column is crucial for the stability of the spine. Watson-Jones ${ }^{3}$ in 1938 was the first to describe the concept of "instability" and stressed on the importance of ligamentous structures in the stability of the spinal column. Nicoll ${ }^{4}$ in 1949 was the first to define the 'Stability of the spine' as a condition in which there is no increased deformity or neurological deficit over time. White and Panjabi $^{5}$ further elaborated on this definition in 1978 and described 'Clinical instability' as a loss in the ability of the spine under physiologic loads to maintain relationships between vertebra in such a way that there is neither damage nor subsequent irritation to the spinal cord or nerve roots and in addition there is no development of incapacitating deformity or pain due to structural changes.

Then Denis ${ }^{6}$ in 1983 used a CT scan based classification of spinal column into three columns, and described instability of the spinal column as an injury to two of these three columns. This coincided with the improvements and widespread use of pedicle screw based posterior fixation systems, enabling surgeons to treat spinal column injuries surgically.
Surgeons have concentrated far too much on the mechanical stability of the spinal column, as defined by various authors, but the pace of improvement and understanding of spinal cord injury and neurological recovery has not kept up. Some good work was done in the use of steroids in acute spinal cord injury, and the randomized trial by Vaccaro et al. ${ }^{7}$ in 1997 was the first one to scientifically try and address the issue of surgical timing on neurological recovery. Despite the concepts of physiological stability of the cord and the first and second hits to the spinal cord being well known in the field of spinal injury rehabilitation, most spinal surgeons continued to concentrate more on spinal column stability rather than neurological recovery of spinal cord injury.

Magerl et al. ${ }^{8}$ went back to the concept of two columns for spinal stability in proposing the AO classification, thus completing a full circle in the concept of spinal column stability over 30 years. Surgeons meanwhile continued to treat even burst fractures without neurological deficit or posterior ligamentous injuries using a variety of surgical techniques in their armamentarium. The improved imaging provided by CT Scans and MRI's, and concerns about degrees of canal compromise on these imaging modalities, contributed greatly to the increased number of surgical treatments, many for canal clearance purposes. Wood et al. published their results of non-operative treatment of burst fractures ${ }^{9}$ and recently updated these results, ${ }^{10}$ which are favourable for non-operative management in the long term. Jaffray et al. ${ }^{11}$ also published on the natural history of burst fractures without neurological deficit. Vaccaro et al. ${ }^{12}$ proposed the TLICS classification in an attempt to help surgeons decide when to operate and when to treat these injuries conservatively. This was a good attempt at trying to fill a gap in the knowledge about appropriate management of spinal injuries. Interestingly, about a quarter of patients described in Jaffray et al.'s paper ${ }^{11}$ had TLICS scores that would suggest surgical treatment, although conservative management did well for these patients. This suggests that the literature is moving in the right direction, but more work needs to be done to improve decision making at grass root levels.

In this day and age of increasing number of spinal surgery techniques, including MIS techniques, it is important to take a look at the history, and not forget that non-operative management of these injuries is a viable option as well. This supplement on spinal trauma is an attempt to make spinal surgeons stop and think about what they are striving to achieve with their treatment and why. The recent surgical trials on results of early versus late surgery for neurological recovery, results of non-operative management of 
such injuries, the clinical art of managing these injuries nonoperatively and the established and emerging spinal imaging techniques have been discussed in different articles. I would encourage all spinal surgeons to contemplate about these issues, especially on the article by DC Jaffray on his opinion on futility of surgical treatment for burst fractures. It is vital, in my opinion, to separate spinal column injuries into those with and without neurological deficit, and those with and without ligamentous injury, and then apply these basic principles to reach the correct decision for treatment.

Surgery is indeed the best option for some patients, but should not be used indiscriminately. The rationale of surgery could be to restore spinal mechanical stability or for neurological improvement or for prevention of further neurological deterioration - but the physiological stability of the cord and the timing of surgery should be kept in mind. It is the job of the spine surgeons to be clear in their own mind about these rationales, and only then will they be able to help patients make the right decisions regarding their treatment.

A quote from Margaret MacMillan is quite apt in this scenario "We can learn from history, but we can also deceive ourselves when we selectively take evidence from the past to justify what we have already made up our minds to do." Strive to move away from untruth towards truth is a saying in the Atharva Veda, and we should definitely try and do that as spine surgeons.

\section{References}

1. Boehler L. Die techniek der knochenbruchbehandlung im grieden und im kriege. Vienna: Verlag von Wilheim Maudrich; 1930.

2. Holdsworth FW. Fractures, dislocations and fracture-dislocations of the spine. JBJS. 1963;45-B:6-20.

3. Watson-Jones R. The results of postural reduction of fractures of the spine. J Bone Joint Surg Am. 1938;20:567-586.
4. Nicoll EA. Fractures of the dorso-lumbar spine. J Bone Joint Surg Br. 1949;31:376-394.

5. White AA, Panjabi MM. The basic kinematics of the human spine: a review of past and current knowledge. Spine. 1978;3:12-20.

6. Denis F. The three column spine and its significance in the classification of acute thoracolumbar spinal injuries. Spine. 1983;8:817-831.

7. Vaccaro AR, Daugherty RJ, Sheehan TP, et al. Neurologic outcome of early versus late surgery for cervical spinal cord injury. Spine (Phila Pa 1976). 1997; 22(22):2609-2613.

8. Magerl F, Aebi M, Gertzbein SD, Harms J, Nazarian S. A comprehensive classification of thoracic and lumbar injuries. Eur Spine J. 1994;3:184-201.

9. Wood K, Buttermann G, Mehbod A, Garvey T, Jhanjee R, Sechriest V. Operative compared with nonoperative treatment of a thoracolumbar burst fracture without neurological deficit. A prospective, randomized study. J Bone Joint Surg Am. 2003;85$\mathrm{A}(5): 773-781$.

10. Wood KB, Buttermann GR, Phukan R, et al. Operative compared with nonoperative treatment of a thoracolumbar burst fracture without neurological deficit: a prospective randomized study with follow-up at sixteen to twenty-two years. $J$ Bone Joint Surg Am. 2015;97(1):3-9.

11. Jaffray DC, Eisenstein SM, Balain B, Trivedi JM, Newton Ede M. Early mobilisation of thoracolumbar burst fractures without neurology: a natural history observation. Bone Joint J. 2016;98-B(1):97-101.

12. Vaccaro AR, Lehman Jr RA, Hurlbert RJ, et al. A new classification of thoracolumbar injuries: the importance of injury morphology, the integrity of the posterior ligamentous complex, and neurologic status. Spine (Phila Pa 1976). 2005;30(20):2325-2333.

Birender Balain MBBS, MS (Orth), FRCS (Orth) ${ }^{\mathrm{a}, *}$

Dr. Hitesh Lal ${ }^{\mathrm{b}}$

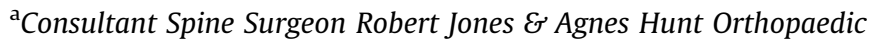
Hospital Oswestry, UK

${ }^{\mathrm{b}}$ Senior Orthopaedic Surgeon and Associate Professor Central Institute of Orthopaedics, Spine Unit VMMC E Safdarjung Hospital, Editor-in-Chief (Journal of Clinical Orthopaedics and Trauma)

Delhi, India

${ }^{*}$ Corresponding author 